only do they resemble each other in their physiological action, but that their toxic action increases with their molecular weight, as I have shown to be the case with the inorganic elements, where, in each isomorphous group, the toxic action increases with the atomic weight of the elements.

In conclusion, I would reprint an extract from a paper published forty years ago :- "A moment's reflection on the problems to be solved will suffice to show that experiments conducted with this class (inorganic) of sub-tances are more likely to furni-h useful results than those made with bodies derived from the animal or vegetable kingdom, although, owing to the striking effects caused by some of these substances, physiologists have mostly directed their attention to them. By so doing, howcver, we are employing re-agents with the properties and composition of which we are imperfectly acquainted, to the neglect of those on the nature of which chemistry has already thrown much light, for not only are we better acquainted with the more purcly chemical properties of inorganic compounds, but their relation to heat, electricity, and molecular polarity bas been to a considerable extent made out." JAMES BLAKE

\section{Disinfection by Heat}

IN Dr. Parsons's Report on Disinfection by Heat (NATURE, vol. xxxiv. p. 583) occurs the statement: "It appears that there are no tables or formula in existence by which the degree of humidity of the air corresponding to a given difference between the wet and dry bulb thermometers at these high temperatures can be ascertained." There are both tables and formulx ; but the tables are the numerical values for the formulæ, and such tables are to be found in Balfour Stewart on "Heat," Dixon's "Treatise on Heat," Blanford 's "Meteorologist's Vade-mecum," and numerous works on the steam-engine.

Let the degree of humidity be represented by $h$; vapourtension at dew-point by $x$; wet-bulb temperature by $t$, its vapour-tension by $f$; dry-bulb temperature by $T$, its vapourtension by $F$; barometric pressure by $b$. Then, the theory of the dew-point gives

and

$$
h=\frac{x}{F}
$$

hence

$$
x=f-\frac{0.382(T-t) b}{1115-0.7 t}
$$

$$
h=\frac{f}{F}-\frac{0.382(T-t) b}{(1115-0.7 t) F} .
$$

The tables give the vapour-tension, consequently if $T, t$, and $b$ are known, $h$ can be found. At these high temperatures the degree of humidity would probably not be required very accurately. If within I or 2 per cent. of accuracy would suffice, the second term may be omitted. This results from the fact that the higher the temperature of the air, the nearer is the dew-point to the wet-bulb temperature.

The quantity sought then is $h=\frac{f}{F}$. Given $T^{\top}=299,299$, and $249 ; t=146, \mathbf{1} 65,190$; and taking $F$ and $f$ in pounds from a table in "Lardner on the Steam-Engine":-

$$
\begin{aligned}
& h=\frac{3.5}{63}=.05 ; \\
& h=\frac{5.5}{63}=.08 ; \\
& h=\frac{9.5}{29}=.32 .
\end{aligned}
$$

Here saturation is represented by unity. This is at once a short and simple method of calculating the degrce of humidity at these very high temperatures. If the barometrical pressure were observed, and the long second term worked out, the results would not be materially different, but would be something less.

II, Offord Road, London, N., October 25

\section{The Beetle in Motion}

MUCH has been written on "the horse in motion." Can any readers of NATURE supply me with references to published matter on the suljject of hexapod progression?

The few observations I have made may be summeil up in a fow words. I use the letters $r$ and $l$ to signify the right and left legs respectively, and number the limbs from before backwards. When walking rapidly the appearance is as if $l \mathrm{I}, r 2$, and $l 3$ moved forward together simultaneously, alternating with $r \mathrm{I}, / 2$, and $r 3$. When the pace is slower it is seen that $l \mathrm{I}$ and $r 2$ start together and come down at about the same time, some-

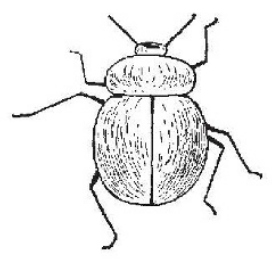

times one sometimes the other being a little the first. Then, lifted almost but apparently not quite at the same time, $l_{3}$ starts. The motion of this leg being somewhat slower, and the limb having further to travel, the foot generally comes to the ground appreciably later than $l_{\mathrm{I}}$ or $r 2$. The general effect is to produce, at the moments of pause between the strides, the position indicated in the figure, which differs considerably from the conventional position delineated by artists who seek to represent the beetle in motion.

University College, Bristol

C. LLOYD MORGAN

\section{The Astronomical Theory of the Great Ice Age}

In Sir Robert Ball's paper on this subject, which appears in your last number $(p, 607$ ), that anthor states that the calculation given "has convinced him that $\mathrm{Mr}$. Croll's theory affords an adequate explanation of the Ice age." It is more in the hope of obtaining from Sir Robert a statement of the grounds of this conviction than for the purpose of controversy that I write this letter.

It will of course be conceded that the frost and snow of a single winter, melted off during the following summer, would not produce an Ice age. But, on Sir Robert Ball's figures, the increase of winter cold at the period in question was accompanied by a corresponding and equal increase of summer heat. Why, then, should the latter prove insufficient to melt the winter accumulation of snow and ice in any locality where it now suffices to melt it ?

The question is one of the joint result of two opposing forces. Both, under the supposed conditions, are intensiged and equally intensified. How does this affect the result? More sr.ow and ice is doubtless formed in the winter, but then more heat is employed in melting it during the ensuing summer. Why, then, was it not melted in any p'ace where it is now melted? $A$ kind of answer to this question may be extracted from the writings of Mr. Croll, but not, I think, a satisfactory one. I am therefore anxious (in common, I am sure, with many others of your readers) to hear the reply of Sir Robert Ball.

Llandudno, October 25

W. H. S. MoNCK

\section{The Enormous Loss from Ox.Warble}

I VENTURE to solicit your co-operation in making some points better known in order that farmers may be better able to protect themselves from the enormous loss from warbles on cattle from the bot-fly, positive proof having been furnished that it largely exceeds $2,000,000 \%$, to $3,000,000 \%$. yearly: To begin : I appeal to those farmers who have somewhat studied the question to make it clear to those who have not done so that each warble lump has a large maggot under it, feeding on the juices of the hide or flesh. The:e lumps many call "health lumps" or "thriving bumps," and seem to frefer that their cattle should have them. It is readily seen how this serious fallacy has arisen, viz. from the fact that the warble lumps begin to show about Christmas (from the growth of the maggot under them), which also happens to be the time that the cattle receive their most nourishing food, and are then warmly housed or sheltered. But there could be no greater mistake than to think that the swellings 